\author{
UNIVERSITY OF CALIFORNIA \\ COLLEGE OF AGRICULTURE \\ AGRICULTURAL EXPERIMENT STATION \\ BERKELEY, CALIFORNIA
}

\title{
INVESTIGATIONS ON THE USE OF FRUITS IN ICE CREAM AND ICES
}

G. D. TURNBOW AND W. V. CRUESS

\section{BULLETIN 434}

September, 1927 
Digitized by the Internet Archive in 2012 with funding from University of California, Davis Libraries 


\title{
INVESTIGATIONS ON THE USE OF FRUITS IN ICE CREAM AND ICES
}

\author{
G. D. TURNBOW1 AND W. V. CRUESS2
}

\section{INTRODUCTION}

Methods of preparing fruit ice cream and water ices vary greatly in different factories and the quality varies correspondingly. Too frequently manufacturers use smaller proportions of fruit than are required for the best quality of product and then attempt to remedy the situation by adding artificial flavor and color.

These investigations were undertaken in order to develop standardized methods of preparation which would improve the quality of commercially prepared fruit ice cream and fruit ices. Once in use, such methods should result in greater consumption of these products, thus benefiting the fruit and ice cream industries, and the consuming public as well.

\section{HEALTHFULNESS OF FRUIT ICE CREAMS AND ICES}

Fruits are an important supplement to the milk products in ice cream. Though they are rich in vitamins $A$ and $B$, milk products usually contain only a relatively small amount of vitamin C. This vitamin, which is particularly important for young children, is found in abundance in many fruits. Orange juice contains vitamin C, which helps to explain the recent widespread use of orange juice in the diet of infants and young children. Vitamin $\mathrm{C}$ is also of great importance to the health of adults.

Most fruits contain acids such as citric, malic, and tartaric, which are beneficial to health, and in addition, mineral salts that during metabolism give residues, basic in character, that tend to counteract the acid residues from a meat and cereal diet. The use of a considerable proportion of fruit in ice cream, therefore, seems desirable from the standpoint of increased healthfulness of the product.

1 Assistant Professor of Dairy Industry and Associate Dairy Technologist in ithe Experiment Station.

2 Associate Professor of Fruit Products and Chemist in the Experiment Station. 
Fruit ices also should be more popular, particularly as desserts during the summer months. Their calorific (heat producing) value is much less than that of many foods, and their natural acidity is thirst quenching and refreshing. There is no excuse for synthetic imitation fruit ices-the cost of the real fruit is low enough to permit of its generous use in ices.

\section{FORMS OF FRUIT USED IN THE INVESTIGATION}

Fruits are available to the ice cream industry as fresh, cold-pack, canned, dried, and candied fruits; fruit juices, fruit syrups, concentrates, jams, preserves, and to a limited extent, fruit powders. There are also fruit products specially prepared for the industry.

In the investigations reported in this paper all of these products were used and their relative desirability for use in ice cream and ices determined.

\section{THE COST OF VARIOUS FRUITS IN ICE CREAM}

It would appear on first thought that fruit ice creams are more costly and less profitable than the plain ice cream. It must be remembered, however, that the "colors," that is, chocolate ice cream, strawberry, and other fruit ice creams usually command a price differential of ten cents a gallon. The increased volume obtained from the addition of the various fruits usually pays for the cost of the fruits and the slight additional cost of manufacture, so that in reality the fruit ice creams, as recommended in this publication, are no more expensive per gallon than plain vanilla ice cream.

\section{INVESTIGATIONS ON THE USE OF FRESH FRUITS IN ICE CREAM}

Investigations at the University of California on the use of fresh fruits in ice cream have shown that the present California state legal minimum of 3 per cent of fruit in fruit ice cream is altogether too low. It is impossible to prepare ice cream having a flavor characteristic of the fruit when such a small proportion is used.

It was also found that the fruit must be thoroughly ripe in order that it may be broken up during freezing. The larger pieces of fruit when too firm or not finely ground, become hard and "icy" in the cream, because their freezing temperature is so much higher than that of the cream. 
Some fresh fruits not heretofore used commercially in ice cream were also used successfully in our experiments. The best of these were fig, persimmon, and avocado.

Comparison of Various Basic Mixes. ${ }^{3}$-In the commercial manufacture of ice cream, a basic mix is prepared containing butterfat, milk solids-not-fat, added cane sugar, gelatin, and the entire mix is pasteurized and homogenized. To this is added vanilla, chocolate, or other flavorings, or fruits. In these investigations two basic mixes were compared. For convenience, these will be designated as basic mixes No. 1 and No. 2.

No. 1 is of the following composition:

10.6 per cent butterfat

14.5 per cent sugar

10.5 per cent skim milk solids

0.4 per cent gelatin

36.0 per cent total solids.

No. 2 is similar in composition to No. 1 when first prepared, but, at the time of freezing, specially prepared skim milk solids are added to increase the total solids to 40 or 41 per cent. The No. 2 mix gave fruit ice creams of smoother texture than mix No. 1. In the formulas given in this publication, basic mix No. 1 is to be used unless otherwise specified. Most ice cream manufacturers use a mix similar to No. 1. When basic mix No. 2 is used, the yield is increased so that the food solids per unit volume is the same as with No. 1.

The experiments will be summarized in the alphabetical order of the fruits. The principal points investigated with each fruit were comparison of varieties, methods of preparing the fruit for use in ice cream, and the determination of best proportion of fruit to be used.

Fresh Apricots.-The effects on the quality of the ice cream of variety, maturity, and method of preparation of the fresh apricots were studied. The Royal and Blenheim varieties were found more satisfactory than the Moorpark and Tilton, because of their more intense and more uniform color, as well as their more uniform ripening. The Tilton is too light in color and the Moorpark ripens very unevenly. Soft-ripe fruit was found much more satisfactory than the firm-ripe, because it was freer from green pieces and richer in flavor and color.

3 For calculation of various mixes see: Turnbow, G. D. and C. M. Titus. An accurate method of calculating ice cream mixes. California Agr. Exp. Sta. Hilgardia 1:57-79. 1925. 
Of the various methods of preparing the apricots, the following was found best. The well ripened apricots were halved and pitted, but not peeled. They were then ground to medium fiineness in a food grinder. To each 8 pounds of pulp was added 2 pounds of sugar. This mixture was boiled three to five minutes.

Uncooked, ground apricot pulp was unsatisfactory because the individual pieces became hard and icy in texture when the ice cream was frozen. Apricot pulp containing much more than 20 per cent of added sugar depressed the freezing point of the ice cream unduly, causing it to be soft under ordinary storage conditions.

In order to obtain sufficient flavor and color in the finished product, it was found necessary to add about 15 per cent of the pulp, prepared as previously described, to the ice cream mix; that is, about 8 pounds to 45 pounds of basic mix. While as little as 10 per cent of the prepared fruit imparted a recognizable apricot flavor to the cream, the flavor was too faint to render the product distinctive.

The following procedure is recommended: Use soft-ripe Royal or Blenheim apricots. Cut in half and pit. Grind to medium fineness. To 8 pounds of pulp, add 2 pounds of sugar. Boil three to five minutes and cool. To 45 pounds of unflavored ice cream mix, add 8 pounds of the prepared apricot pulp and freeze in the usual manner to 100 per cent yield; that is, to about $113 / 4$ gallons.

Fresh Avocados.-Several ice cream manufacturers, who have been persuaded to prepare avocado ice cream commercially, have found that there is a potential market for limited quantities in the high class hotel and restaurant trade. When production of avocados shall have increased sufficiently to make the cull fruit available at the price of other fruits used in ice cream, there should be a good demand for avocado ice cream as a "special" for the regular trade, because the product is of very attractive appearance and of rich, pleasing flavor.

It was found, as with other fruits, that thoroughly ripe fruit (in this case, soft-ripe) was best for the purpose. Heating even to 175$180^{\circ} \mathrm{F}$ was found to injure the flavor seriously. On standing in the air, avocado pulp soon darkened through oxidation. The best results were obtained by grinding the peeled and pitted fruit to a fine paste and adding immediately about 18 per cent of it by weight to unflavored ice cream mix (that is, 10 pounds of the fruit to 45 pounds of mix), and freezing in the usual manner to 100 per cent yield, or to about 12 gallons.

Avocado ice cream is pale green in color, smooth in texture, and resembles pistachio nut ice cream in flavor as well as in appearance. 
Fresh Bananas.-While the banana is not a California fruit, for the sake of completeness it was included in the fruit ice cream experiments. It was found unnecessary to reinforce the banana flavor with artificial flavor, provided sufficient fruit was used. The following recommended procedure is the result of trials made with commercialsized lots of ice cream by the Dairy Division of the University of California :

Peel and grind enough thoroughly ripe bananas to give 3 to 4 pounds of ground fruit. Add to 45 pounds of unflavored mix and freeze to 100 per cent yield. A small amount of yellow color may be added if desired.

Fresh Blackberries.- These gave an ice cream of rather unattractive color, and not very distinctive in flavor. Fresh blackberries are recommended for use in water ices rather than in ice cream.

Fresh Cherries.-Because of the popular prejudice against the mixing of fresh cherries and cream, the fresh cherries were not used in these investigations. See experiments with maraschino cherries on page 18.

Fresh Figs.-Fresh figs are obtainable at moderate cost in August and September in the interior valleys of California. Although not generally known, fig ice cream possesses unusually pleasing flavor and general quality, and should prove popular.

Three varieties, the Black Mission, Calimyrna, and Kadota, were compared. The Kadota and the Mission, because they lack in flavor and have very small seeds, were not as satisfactory as the Calimyrna.

While fairly good results were obtained by adding the finely ground, unsweetened, and uncooked figs to the mix, there was, as with apricots, a tendency for the larger pieces of pulp and skin to treeze to an icy consistency and to cause the cream to be rough in texture. Much better results were obtained by cooking the ground fruit with sugar before adding it to the mix.

About 15 per cent by weight of the cooked fresh figs was necessary to give a characteristic flavor and appearance to the cream; 20 per cent gave a better product than did 15 per cent.

The following procedure is based on these experiments: Use softripe figs. Cut off the stems. Grind the fruit to medium fineness. To 7 pounds of figs add 11/2 pounds of sugar. Boil three to four minutes. Cool and use with 45 pounds of ice cream mix. Freeze to 100 per cent yield; that is, to about $11 \frac{1}{2}$ gallons. 
Fresh Oranges.-Although orange ice is much better known and more popular than orange ice cream, there is a considerable demand for the latter. Most published formulas recommend too small a proportion of orange juice.

The best method of extracting the juice was found to be by "burring" the halved oranges on a rapidly revolving metal or porcelain cone. Small juice extractors having such a cone are in common use in soda fountains. Pressing the whole or crushed fruit gave a juice of less desirable flavor and with too little of the highly colored pulp. See figure 4.

The addition of some lemon juice and sugar was found desirable.

The following procedure is recommended: Cut the oranges in half and extract the juice on a revolving cone. Strain through a screen to remove seeds and coarse pieces of pulp and skin. To 3 quarts of orange juice, add 1 pint of lemon juice and 3 pounds of sugar. For 3 quarts of juice, about $3 \frac{1}{2}$ dozen oranges of average size are required; for one pint of lemon juice, 1 dozen lemons are required. Dissolve the sugar by stirring. Add to 45 pounds of ice cream mix. Add a few drops of orange oil (approximately 8 drops) and a small amount of orange color.

Orange oil stored at room temperature soon becomes "rancid" or "turpentiney" in odor and flavor because of oxidation and other changes in the terpenes. To prevent this very undesirable change, the oil should be stored at about $32^{\circ} \mathrm{F}$. Only small quantities should be purchased, so that it may be used before it spoils in flavor.

Fresh Peaches.-Some varieties of peaches were more suitable than others for use in ice cream. The common canning varieties of clingstones lacked flavor and required prolonged cooking to make them soft enough for use. The common drying and shipping freestones, such as the Muir, Crawford, Lovell, and Elberta, also lacked flavor; nevertheless, they were superior to the canning clingstones in texture and flavor. The Lovell was best but was not so satisfactory as the highly flavored, soft textured, early table peaches that were purchased in the open market under the name of Strawberry and Carmen. These gave a cream of pronounced peach flavor.

With the other varieties, i.e., Muir, Crawford, Lovell, etc., it was found necessary to use a relatively large proportion, about 20 per cent by weight, of fruit in order to obtain a cream readily recognized as peach. 
Cooking with sugar before the fruit was added to the ice cream mix prevented the formation of ice crystals after freezing.

The following procedure is recommended: Use soft-ripe, freestone peaches, such as the Lovell or a soft easily peeled table variety. To peel, dip in boiling water for 30 to 60 seconds or steam for one to two minutes. Chill in cold water and life the skins from the fruit. Remove pits. Grind the fruit. To 10 pounds of the pulp, add 3 pounds of sugar. Boil gently three to five minutes and cool. Add to 45 pounds of unflavored ice cream mix. If yellow fruit is used, no added color is needed. Freeze to about 100 per cent yield; that is, to about $12 \frac{1}{2}$ gallons.

Fresh Bartlett Pears.-Bartlett pears are plentiful and low priced during the season, July 15 to September 1, and are obtainable from cold storage until January 1. They were found only fairly satisfactory for ice cream. Crushed or ground fresh pears darkened very rapidly. On this account they were unsatisfactory unless heated to destroy the enzyme responsible for the darkening. Like the canning and drying varieties of peaches, Bartlett pears were somewhat lacking in flavor; about 20 per cent by weight had to be used. The flesh being firm, preliminary cooking to soften the texture was found necessary.

The following procedure is recommended: Use thoroughly ripe (but not overripe) Bartlett pears. Peel, cut in half, and grind fine. To 10 pounds of the pulp, add $2 \frac{1}{2}$ pounds of sugar. Boil about five minutes. Cool and use with 45 pounds of mix, freezing to 100 per cent yield or to about 12 gallons. A small amount of yellow color improves the appearance.

Fresh Persimmons.-At the request of the Southern Counties Farm Bureau Federation of California, persimmons were used experimentally for the preparation of various products, among them persimmon ice cream. Soft, ripe Hachiya persimmons were peeled, the stems were removed, and the fruit was ground to a jam-like consistency. One pound of sugar was added to each 3 pounds of pulp. The sweetened pulp was added to basic ice cream mix to the extent of about 18 per cent by weight; that is, about 10 pounds to 45 pounds of mix. These quantities yielded about 12 gallons of finished cream.

The resulting cream was a rich golden yellow in color and had a pronounced but very pleasing flavor, smooth texture, and good keeping quality in the hardening room. It is believed that this ice cream affords a very good outlet for surplus persimmons.

Fresh Raspberries.-Raspberries behave like strawberries in ice cream. Four pounds of the washed and crushed or ground berries 
added to 45 pounds of mix containing one-half the amount of vanilla flavor used in vanilla ice cream has been found to give a very good raspberry ice cream. A small amount of added color is usually necessary to give a cream of the color expected by the consuming public.

Fresh Strawberries.-The experiments show that the minimum legal limit is altogether too low for strawberries as well as for other fruits. Not less than 6 per cent of strawberries should be used. All varieties of strawberries are not equally desirable for use in ice cream. The Banner, which is the most common variety grown in this state, lacks color, particularly near the center of the berry. Furthermore, the berries are often hollow. The highly colored varieties that are solid in texture and red in color to the core are to be preferred. The Marshall has been used by the Dairy Industry Division and has been found excellent for the purpose. It ean usually be obtained directly or by dealers from a few growers in the important berry growing districts in California, but is difficult to obtain on the open market. The Ettersberg and Trebla are also desirable preserving varieties grown in the Pacific Northwest and should be equally as good as the Marshall for use in ice cream.

The following procedure is recommended: Hull and wash thoroughly ripe, well colored berries and crush or grind them. Add 4 pounds of the berries to 45 pounds of ice cream mix containing onehalf the amount of vanilla flavoring used in vanilla ice cream. Freeze to 100 per cent yield or to about $103 / 4$ gallons. Four pounds of berries correspond to about 8 per cent fruit by weight.

A small amount of color may be added; no artificial flavor is required and should not be added, as it very seriously detracts from the natural berry flavor.

\section{INVESTIGATIONS ON THE COLD-PACKING OF FRUITS AND THEIR USE IN ICE CREAM}

Strawberries, raspberries, and blackberries are stored at freezing temperatures in commercial quantities for the fruit preserve and ice cream industries. Previous investigations ${ }^{4}$ have demonstrated that most of the berries and deciduous fruits grown in California can be preserved with practically all of their fresh flavor and color, when properly prepared and stored in sealed containers at $15^{\circ} \mathrm{F}$ or less.

${ }^{4}$ Cruess, W. V., E. I. Overholser, and S. A. Bjarnason. Storage of perishable fruits at freezing temperatures. California Agr. Exp. Sta. Bul. 324:2543. 1920. 
While freezing storage softens the fruit texture, this softening in no way injures, but rather improves, the value of the fruit for use in ice cream.

In connection with the investigations on the use of fruits in ice cream, experimental lots of various fruits were prepared and stored at low temperatures both at Davis and at Berkeley.

Determination of the Rate of Cooling. ${ }^{5}$ - In commercial cold storage establishments, berries and crushed fruits packed in 50-gallon barrels

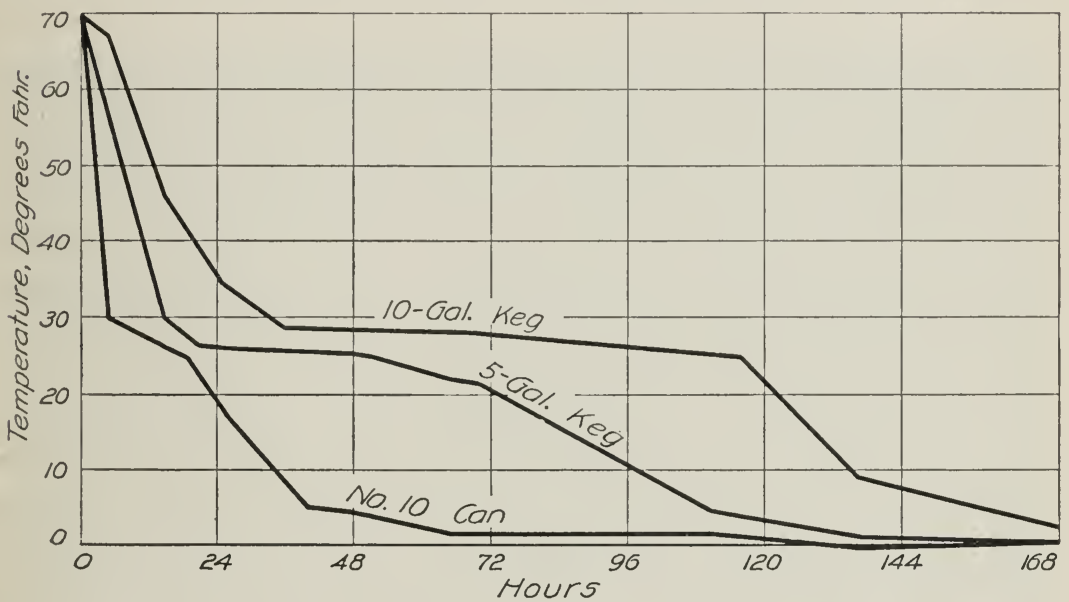

Fig. 1.-Relative rates of cooling for crushed fruit in various size containers.

and placed at once in freezing storage sometimes undergo fermentation before the fruit cools sufficiently to prevent yeast growth and activity. In order to obtain accurate information on the rate of cooling of crushed fruit under practical conditions a 10 -gallon keg, a 5-gallon $\mathrm{keg}$, and a No. 10 can (slightly less than 1 gallon capacity) were filled with orushed fruit at room temperature. They were fitted with resistance thermometers and placed in the freezing storage room in IIilgard IIall at a temperature varying from about $1^{\circ} \mathrm{F}$ below zero to about $5^{\circ} \mathrm{F}$ above zero.

By means of an instrument; outside the cold room, but connected to the resistance thermometers by suitable wire leads, the temperature at approximately the center of each container was read at frequent intervals, with the results illustrated in figure 1.

5 Conducted in cooperation with George Marsh, former student assistant in Fruit Products. From Cruess, W. V. Utilization of surplus plums. Calif. Agr. Exp. Sta. Bull 400. 1926. 
The No. 10 can cooled very quickly, reaching $32^{\circ} \mathrm{F}$, the freezing point of water, in less than five hours; the 5-gallon keg reached $32^{\circ} \mathrm{F}$ in a little less than sixteen hours, and the 10-gallon keg, in about thirty hours. At about $26^{\circ} \mathrm{F}$ cooling in all three containers became very slow for about a twenty-four hour period in the kegs and for about eight hours in the No. 10 can. This represents the freezing of the fruit to a solid piece of ice with consequent retardation of heat transfer. At the time of freezing, the temperature of the entire contents of the containers probably became that of the freezing temperature of the fruit, about $26^{\circ} \mathrm{F}$. The thermometers being located at the centers of the containers would not register any further change until the "cold" had again penetrated to the centers, causing the temperature again to drop.

If the fruit in the 10-gallon keg had been in poor condition, that is, badly bruised and infected with yeast before packing, it would probably have fermented for several hours before reaching a temperature low enough to arrest fermentation. In 50-gallon barrels, the margin of safety is of course still less.

Comparison of Open and Sealed Containers.-In commercial practice, berries for making preserves and ice cream are stored in open crates or baskets at a freezing temperature, or are crushed in open barrels. Both of these methods of storage were found objectionable. In open baskets or crates, the fruit lost much of its flavor and, on thawing, tended to become brown in color. In open containers such as barrels they absorbed flavor from other products stored in the same room with the fruit.

Number 10 fruit cans, enameled inside, proved very satisfactory and inexpensive containers. A small hand-power can sealer was used in sealing the cans.

Recently, the can manufacturers have produced for the cold-pack industry a special 5-gallon can fitted with a 6 -inch friction seal opening in the top and coated inside and out with a protective enamel that prevents rusting and reduces corrosion. This container can be recommended to those ice cream manufacturers who wish to store fruit for their own use. No equipment is needed for sealing the can, and with proper care it can be used for several seasons. It is illustrated in figure 2.

Barrels are not so satisfactory as cans for the following reasons. When opened for use, only a small portion of the contents of the barrel is used; the remainder stands in the open barrel usually for several weeks before all of it is used. It oxidizes near the surface, 
turning brown, loses flavor, and usually acquires a "cold storage" odor and flavor. The contents of a No. 10, or of a 5-gallon can, are used at once or within a day or two after opening, and consequently have no opportunity to deteriorate greatly in quality.

Comparison of Storage in Syrup and with Dry Sugar.-Cold-pack berries for the trade are usually packed with sugar. In these experiments, various fruits were packed in water in sealed containers, with syrups of various sugar concentrations; and with various proportions of dry sugar. Berries were found most satisfactory for use in ice

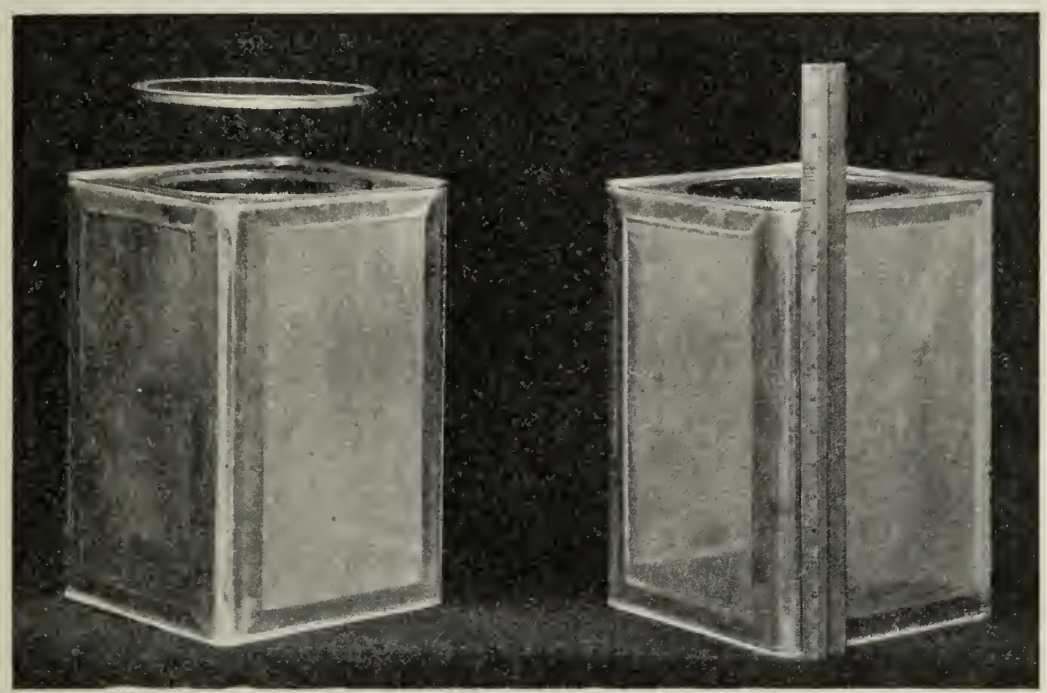

Fig. 2.-Five-gallon enameled can for cold-packing of fruits.

cream when packed with half their weight of sugar; that is, 1 part of sugar by weight to 2 parts of berries. Crushing the berries before packing improved them for use in ice cream. With less sugar, the flavor was not so well retained; with more, the fruit was too sweet and gave a soft cream, because the excessive sugar content depressed the freezing point unduly. In water and in syrups, the berries tended to float on thawing, giving a large volume of syrup; and the color tended to diffuse into the liquid, causing the berries to be too pale in color.

Crushed apricots, peaches, figs, persimmons, avocados, and plums were most satisfactory when mixed with 1 part of sugar to 2 of fruit and packed in sealed containers.

Sliced fruits and whole figs were best packed in a syrup of medium density; that is, of about 50 per cent sugar content, made of equal parts sugar and water, and stored in sealed containers. 
Effect of Length of Storage.-Strawberries, loganberries, blackberries, raspberries, and apricots have retained their flavor perfectly in sealed cans at zero to $15^{\circ} \mathrm{F}$ for more than three and a half years. Peaches after one year's storage had acquired a slight bitter almond flavor, but were still satisfactory for most purposes.

Procedure Recommended for Cold-packing Various Fruits.-The following methods of preparing and cold-packing various fruits are recommended:

(a) With berries, all varieties: Stem, sort and wash thoroughly ripe berries. Pack 2 parts, by weight, with 1 part, by weight, of sugar in enamel-lined friction top, 5-gallon cans or in enamel-lined, No. 10 fruit cans, jolting the cans vigorously. In 5-gallon cans fill to about $1 \frac{1}{2}$ inches of top. Seal and store at once at zero to $15^{\circ} \mathrm{F}$.

(b) With apricots, avocados, persimmons, and peaches: Use softripe fruit. Pit the apricots; peel and pit the avocados and peaches; pit the persimmons, seedless preferred. Grind the fruit. Add 1 pound of sugar to each 3 pounds of pulp and seal and store as directed for berries.

(c) With fruit juices: Extract the juice from grapes and berries by crushing and pressing; from citrus fruits, by a revolving cone. To each gallon of juice, add 3 pounds of sugar. Fill jugs or 5-gallon bottles about three-quarters full. Cork and store at zero to $15^{\circ} \mathrm{F}$. Do not fill glass containers too full, or they will burst because of the expansion of the juice on freezing. Juices prepared in this manner and stored in sealed containers at zero to $10^{\circ} \mathrm{F}$ have retained their fresh flavor and color in tests for more than four years.

Using Cold-pack Fruits in Ice Cream.-It was found necessary to thaw the frozen fruits before using in order that the ice cream would be free of large ice crystals. The fruit was then ground or crushed and used in the same proportions and in the manner described for the fresh fruits.

\section{INVESTIGATIONS ON THE USE OF CANNED FRUITS IN ICE CREAM}

While canned fruits are not very generally used in ice cream at present, several varieties were used in our experiments and gave excellent results. They are much less costly than the same fruits specially prepared for the ice cream industry and are equally as good or better for the purpose.

Comparison of Different Varieties of Canned Fruits.-Commercially canned peaches, pears, pineapple, apricots, and figs were 
used in the preparation of ice creain. It is already well known that commercially canned crushed pineapple is satisfactory for this purpose. The only work done with pineapple, therefore, was to determine what treatment should be given it before adding to the mix.

Canned peaches lacked flavor, although when 20 per cent or more, by weight, was added to the mix (about 11 pounds to 45 pounds of mix), a fairly satisfactory ice cream resulted. The freestone varieties possessed somewhat more flavor than the clingstone varieties.

Pears gave a satisfactory, although not unusually distinctive ice cream, when sufficient fruit, about 20 per cent by weight, was used.

Canned apricots gave excellent results, the canned fruit being equal in every way to the fresh. Some ice cream makers already use canned apricots, although the use of specially prepared crushed apricots is more common.

Canned figs were found to be very desirable for use in ice cream and cheaper than the fresh fruit, if the proper grade of canned figs is used.

Comparison of Different Grades of Canned Fruits.-There are five commercial grades of California canned fruits. These are: Fancy, which consists of fruit of the highest quality, canned in a heavy syrup ; Choice, fruit of excellent quality canned in medium heavy syrup; Standard, fruit of medium quality canned in medium light syrup; Seconds, fruit of second quality canned in very dilute syrup; and Water or Pie, sound fruit that is overripe, or trimmed, or slightly blemished, canned without added syrup or in water only.

The different grades of the more important canned fruits were compared experimentally for use in ice cream. Unexpectedly, the pie grade was found much superior to the other grades for use in ice cream, principally because there was much more fruit of this grade to each ean and much less waste liquid. This grade is much lower in price than the other grades and at present is the most difficult grade for the canner to sell. It may be purchased by the case of six, No. 10 cans, direct from canneries, or from canned food brokers, jobbers, and wholesalers.

There are two classes of pie grade canned fruits: that known as "solid pack," and that known as "water pack." The "solid pack" is by far the better for use in ice cream and should be specified when ordering.

If ordered in advance of the fruit season, some canners will prepare canned puree from apricots, peaches, and pears. This product is ready to use and is not costly. In experiments conducted on a semi- 
commercial scale by P. F. Nichols of the Fruit Products Laboratory, it was found that an excellent quality of canned crushed pears can be made by commercial canners from pie grade pears by mixing the crushed fruit with 1 part of sugar to 4 parts of fruit, and then canning and sterilizing. Tests conducted by the authors show that this product is well adapted to use in ice cream.

Preparation of the Fruit.-In some experiments the canned fruits of pie grade were merely ground and added to the mix; in others, they were cooked with sugar after grinding. Apricots, pears, and figs were found to be satisfactory if added without cooking with sugar, and treated as directed below. The ground peaches and crushed pineapple were improved by cooking 6 pounds (one No. 10 can) of the fruit with 2 pounds of sugar for five to ten minutes. This also prevented complete freezing of the pieces of fruit. The other fruits were so finely ground, or rubbed through a sieve, that there were no large pieces of fruit to become icy in the cream.

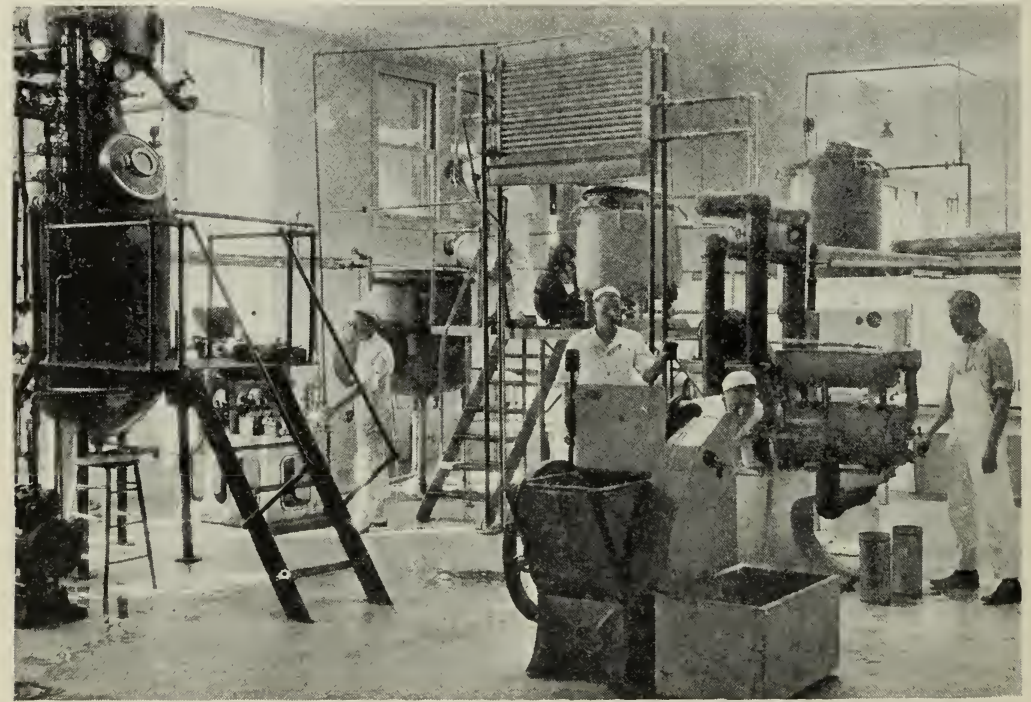

Fig. 3.-Forty-quart freezer and other equipment used in these experiments; Dairy Industry Division, University of California, at Davis.

Directions for the use of Various Canned Fruits.

(a) Apricots: Grind or rub through a sieve the contents of one No. 10 can of pie grade apricots. Add to 45 pounds of unflavored ice cream mix and freeze in the usual manner to about 100 per cent yield, that is $111 / 2$ gallons.

(b) Figs : For a cream of mild fig flavor, grind the contents of one No. 10 can of solid pack pie grade Calimyrna figs and add to 45 
pounds of unflavored mix. For a "health" cream of very rich fig flavor, use 10 pounds (about one and two-thirds No. 10 cans) of the ground figs to 45 pounds of mix. Freeze to about 100 per cent yield, that is, about 13 gallons.

(c) Peaches: Grind the contents of two No. 10 cans of pie grade peaches and add 4 pounds of sugar. Boil gently five minutes and cool. Add about 11 pounds of the prepared fruit to 45 pounds of ice cream mix flavored with about one-third the amount of vanilla flavoring used for vanilla ice cream. The addition of a small amount of peach flavor may be required. Freeze to about 100 per cent yield, that is, 12 gallons.

(d) Pears: Proceed as with apricots but use 11 pounds of the finely ground, solid pack, pie grade pears with 45 pounds of unflavored. ice cream mix. A small amount of yellow color may be desirable. If canned crushed pears described on page 16 are obtainable, use 11 pounds with 45 pounds of mix, without grinding or cooking.

(e) Crushed Pineapple: To the contents of one case of No. 10 cans of crushed pineapple, add 35 pounds of sugar. Boil three minutes. Cool and use $1 / 2$ gallon of the cooked fruit with 45 pounds of ice cream mix. $^{6}$

\section{INVESTIGATIONS ON THE USE OF FRUIT PRESERVES IN ICE CREAM}

Fruit preserves specially prepared for the ice cream trade as well as those prepared commercially for the table were used experimentally in ice cream. The principal objections to most of such preparations are their high cost and high sugar content. Pie grade canned figs, apricots, pears, and peaches are much lower priced than the corresponding fruit preserves and more suitable for use in ice cream. When sufficient of the ground fruit preserves was used to impart to the ice cream the characteristic fruit flavor and appearance, the high sugar content of the fruit so depressed the freezing point that a too soft ice cream was obtained.

Berry preserves were open to the same objections and were found to be considerably less desirable than the cold-pack (frozen) berries for use in ice cream.

For these reasons, the cold-pack and commercially canned fruits are to be preferred to the fruit preserves.

6 This is the formula in use in Hage's ice cream factory of San Diego and in the Dairy Industry Division, Davis, California. 


\section{INVESTIGATIONS ON THE USE OF FRUIT JAMS IN ICE CREAM}

Fruit jams for the table are usually made by cooking together about equal weights of crushed fruit and sugar, and usually contain more than 50 per cent sugar when cooked. A number of fruit jams were tried in ice cream but the objections of high cost and high sugar content found with preserves applied with nearly equal force to jams. While they can be used, they are much less satisfactory and are more costly than the corresponding pie grade canned fruits and cold-pack fruits.

\section{INVESTIGATIONS ON THE PREPARATION AND USE OF MARASCHINO CHERRIES IN ICE CREAM}

Cherry ice cream made with cherries prepared by the maraschinu process is of considerable commercial importance, and most factories have found satisfactory methods of making cherry ice cream. There is, however, a considerable demand from ice cream makers for information on methods of preparing the maraschino cherries from the fresh fruit. Most ice cream factories possess the equipment necessary, the principal requirements being a steam-jacketed kettle or other means of boiling several gallons of syrup and fruit.

Numerous experiments have been conducted in the Fruit Products and Dairy Industry Laboratories on the various steps of the maraschino process. The more important of these experiments have been reported by A. H. Nouty in a recent Master's 'Thesis in Fruit Products. Since these experiments are of more interest to canners and preservers than to ice cream makers, they will be published elsewhere and only the working directions based on them will be given here.

There are several important steps in the process. The first of these is storage of the fresh cherries in dilute sulphurous acid solution to harden the tissues and bleach the color. The cherries are then stemmed, pitted, and boiled in several changes of water to remove the sulphurous acid and to soften the texture of the fruit. They are then boiled and stored for short periods in artificially colored and flavored syrups of progressively increasing sugar concentration.

Preparation of Maraschino Cherries.-The following procedure has given good results (after J. H. Irish) :

(a) Storage in sulphurous acid brine: Place firm-ripe Royal Anne cherries in a barrel or keg. Prepare the following solution: 
Water 23 gallons

Sulphurous acid solution (strength $6 \%$ ) .................. 2 gallons

Salt

10 pounds

Fill the container with this solution; seal and store in a cool room, preferably below $60^{\circ} \mathrm{F}$.

(b) First boiling: After a storage of 4 weeks or longer, open the barrel or keg and discard the solution. Stem and pit the cherries. Place them in a kettle and cover with water. Boil 5 minutes and discard the water. Boil with three to four additional lots of water for periods of about 5 minutes each; that is, until the cherries are tender and are practically free from all "sulphur" taste.

(c) Syrup treatment: Prepare a syrup of the following composition :

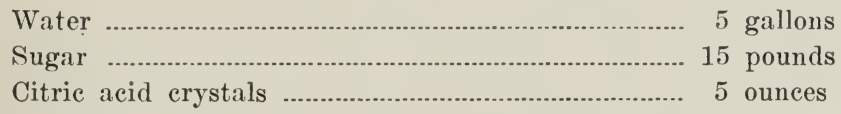

Certified red color, preferably Ponceau $3-\mathrm{R}$ and

Amaranth mixed, to give the desired tint.

Boil the cherries in this solution for 3 to 4 minutes. Set aside overnight. Then drain off the syrup and test it with a Baumé or a Balling hydrometer and add the dissolved sugar to make the syrup to $35^{\circ}$ Balling or $18^{\circ}$ Baumé; or if a hydrometer is not at hand, add to each 5 gallons of syrup about 25 pounds of sugar. (The use of a hydrometer is strongly urged; uniform results cannot be obtained without one.)

Boil the fruit and syrup 3 to 4 minutes and set aside overnight.

Repeat the previous day's operations, bringing the syrup to $40^{\circ}$ Balling or to $21^{\circ}$ Baumé by adding sugar, or merely add another 6 pounds of sugar to 5 gallons of syrup. If needed, also add red coloring. Add cherry flavoring to suit or a few drops of bitter almond oil and proceed with step $d$.

(d) Sterilization: Heat syrup and fruit to boiling. Pack into glass fruit jars fitted with rubbers and glass tops. Seal loosely. Place in a steam box or in a bath of hot water and heat in live steam or in boiling water for 20 minutes. Remove and seal tightly.

A simpler method of preservation is as follows: Heat cherries and syrup to boiling. Set aside overnight. Place in wooden kegs or in heavily paraffined ice cream cans and store in the hardening room at zero to $15^{\circ} \mathrm{F}$.

Using the Maraschino Cherries in Ice Cream.-Grind the cherries and add $23 / 4$ pounds to 45 pounds of unflavored mix. Add color and flavor to suit. 
INVESTIGATIONS ON THE USE OF FRUIT JUICES, SYRUPS, AND CONCENTRATES IN ICE CREAM

Orange juice is the only fruit juice that is very well suited to use in ice cream. Although grape, berry, and other fruit juices and also syrups and concentrates made from them, were used in ice cream with fair success, they were much more satisfactory in water ices and will be discussed in that connection. See page 25 .

The preparation of ice cream with fresh orange juice is described on page 8 . Orange syrup made with sugar can be substituted for the juice, if it is first diluted with three times its volume of water and if the same volume of the diluted syrup is used as is recommended for juice, page 8 . No, additional sugar is needed.

Orange concentrates (orange juice slightly sweetened and concentrated in vacuo to a thick consistency) of good quality are now obtainable and may be used to replace most of the fresh juice in any good, orange ice cream formula. However, the use of some fresh orange juice is highly desirable in order to furnish the fresh fruit flavor which the concentrate lacks. The following formula has given satisfactory results :

Orange concentrate ............................................ 1 pound
Water ............................................................ 5 pounds
Fresh orange juice ................................................. 1 pound

Add to 45 pounds of ice cream mix and add color and orange oil to suit. One pound of concentrate is equivalent to about six pounds of fresh juice.

\section{INVESTIGATIONS ON THE USE OF CANDIED FRUITS IN ICE CREAM}

Considerable quantities of candied fruits are used in special ice cream such as tutti-frutti and in frozen puddings. The broken, ground or chopped candied fruits, representing wholesome fruit unsuitable for packing for the candy trade, can be purchased at moderate cost from candied fruit factories or ice cream supply houses. These products are satisfactory for the purpose intended. As the process of preparing candied fruits is troublesome and costly, and as the average ice cream factory uses only relatively small quantities, there is no need for the ice cream manufacturer to make candied fruits. The process is not difficult, but requires about three weeks or longer. ${ }^{7}$

7 Directions for making fruit candy may be found in: Cruess, W. V. and Agnes O'Neill. The home preparation of fruit candy. California. Agr. Ext. Service Cir. 10:1-28. 1927. 
The larger pieces of candied fruits, such as candied figs or apricots cut in half or candied peaches or pears cut in quarters, may be used in aufait creams; that is, they may be placed between layers of different kinds of cream for the making of bricks. When used in this manner, they add greatly to the appearance of the cream.

\section{INVESTIGATIONS ON THE USE OF DRIED FRUITS IN ICE CREAM}

A number of different dried fruits were prepared in various ways and used experimentally in ice cream. Of these, prunes and raisins appear to have the greatest commercial possibilities. While dried apricots, peaches, and figs can be used in ice cream, the canned and cold-pack fruits of these varieties are much better for the purpose and much more convenient to use. For these reasons most attention will be given to prunes and raisins in the following discussion.

Prunes.-Prunes are used in the diet largely on account of their well known physiological effect. They are of particular value as a food for children and convalescents. Unfortunately, however, many people, especially some in the two classes of consumers mentioned above, are not fond of prunes and if they eat them at all, do so largely as a matter of duty.

Experiments with prune ice cream resulted in a product possessing a very attractive appearance and pleasing flavor. It is believed that prunes in this form will appeal to any one who likes ice cream, and that prune ice cream will be especially desirable for use as a food for children and for convalescents whether in hospitals, sanitariums, or in the home.

Ice cream was made with prunes prepared in the following ways:

(a) With canned prune pulp: ${ }^{8}$ The most satisfactory of the methods tested of preparing prunes for the ice cream trade was found to be as follows: The dried prunes were boiled in water until soft and were then passed through a medium-coarse screen in a tomato pulper, which separated the pulp from the pits. The resulting pulp was heated almost to boiling, canned, and sealed hot, and then sterilized in boiling water. The product thus prepared contained about 60 per cent of water. It can be prepared at small cost by any fruit cannery, and if a demand is created for it arrangements can be made to have it prepared for the ice cream trade.

8 This process of preparing prunes was developed by E. Mrak, a graduate research assistant in Fruit Products. 
An ice cream for the soda fountain trade and for dessert purposes is made by using 20 per cent by weight of this pulp with 45 pounds of unflavored ice cream mix. This corresponds to about 11 pounds to 45 pounds of mix. Freeze to about 12 gallons. For a health cream, a mix containing about 30 per cent of prune pulp was satisfactory; this corresponds to the addition of pulp in the ratio of 20 pounds to 45 pounds of mix, or 10 pounds to $221 / 2$ pounds of mix. The basic mix must contain in this case about 12 per cent of fat in order that the finished cream will contain more than the legal minimum of 8 per cent.

The "health" cream is best served fresh, as it tends to become somewhat rough in texture on prolonged storage in the hardening room. With the lower proportion of prune pulp, the ice cream retains its texture very well in the hardening room.

(b) With cooked prunes: While considerable trouble and time are involved, it is possible for the ice cream maker to prepare prune pulp from the dried fruit. A number of methods of cooking the prunes were compared and the most satisfactory was found to be about as follows :

To 7 pounds of dried prunes add 4 quarts of water. Bring to boiling and set aside overnight. Then boil gently until soft; usually 20 minutes will be sufficient. Discard the water in which the prunes were cooked. Rub the fruit through a colander or coarse screen to remove pits or pit by hand and grind in a food chopper. Use as directed in (a) for canned prune pulp.

No sugar should be added to prunes cooked for use in ice cream.

(c) With pitted prunes: Small pitted prunes were used in some tests. These may be purchased from packers of dried prunes. They were cooked with about $1 \frac{1}{2}$ volumes of water, ground, and used as previously described for pulp and cooked prunes. Unfortunately, these prunes carry a considerable number of pieces of broken pits and for this reason are of doubtful value for use in ice cream.

(d) With canned ready-to-serve prunes: Prunes canned in light syrup in No. 10 cans are obtainable but are of course more costly than the plain dried prunes. Canned prunes used in ice cream were satisfactory. They were rubbed through a screen to remove pits, and the pulp was mixed with the syrup before adding to the ice cream mix.

Raisins.-Raisins have been used in ice cream to a considerable extent in the eastern states. Usually, however, the mistake has been made of using Thompson seedless instead of Muscat raisins. The 
Thompson seedless is poorly adapted for this purpose because it is almost wholly lacking in flavor. On the other hand, Muscat raisins possess a very pronounced flavor that is pleasing and may be readily recognized in the ice cream. A mixture of Muscat and Thompson seedless raisins is fairly satisfactory. A number of experiments were made to determine the most satisfactory method of preparing the raisins for use in ice cream and to determine the proper amount to be added to the mix.

(a) With bulk raisins: Seeded bulk Muscat raisins of bakers' quality and bulk Thompson seedless raisins were used in the experiments. The raisins were soaked and cooked with various proportions of water; some were ground before use, others were used whole, and various amounts of the different preparations were added to basic ice cream mix. As stated above, the Thompson seedless raisins used alone proved unsatisfactory because of lack of distinctive flavor. Less than 10 per cent of Muscat raisins gave an ice cream of weak flavor; the best proportion was found to be about 15 per cent by weight; that is, about 8 pounds of the prepared raisins to 45 pounds of mix.

When whole raisins only were added, the appearance was not so satisfactory and the flavor was less pronounced than when about half of the raisins were ground and the remainder added whole. A satisfactory combination was equal weights of ground Muscat raisins and whole Thompson seedless raisins.

When more than 40 per cent of water, i.e., 4 pounds of water to 6 pounds of raisins, was used, the ice cream was pale in color and too watery, giving a rough cream. From 20 to 30 per cent added water was found best. When no water was added, the raisins were tough after the cream was frozen; also they tended to sink toward the bottom of the ice cream cans or brick pans unless the cream was unusually stiff when drawn.

Based on these findings, the following alternative procedures are recommended :

(1) To 5 pounds of Muscat raisins add 3 pints, or 3 pounds, of water. Mix well. Warm gently to nearly the simmering point, that is, to about $165^{\circ} \mathrm{F}$, but do not allow to boil. Set aside about two hours; stir occasionally during this period to facilitate absorption of the water. Grind one-half of the raisins. Mix with the unground raisins and the syrup. Add to the 45 pounds of unflavored ice cream mix and freeze to 100 per cent yield, or about $11 \frac{1}{2}$ gallons. 
(2) To $21 / 2$ pounds of Muscat raisins, add $1 \frac{1}{2}$ pounds of water; heat, soak, and grind all of the raisins as directed above. Prepare $2 \frac{1}{2}$ pounds of Thompson seedless in similar manner but do not grind. Mix the ground Muscats, whole Thompson seedless, and the syrup. Add to 45 pounds of mix. Freeze to about $11 \frac{1}{2}$ gallons.

(b) With commercially canned raisins: Some seeded Muscat raisins are canned commercially and are practically ready to use in ice cream. If 4 pounds of the canned raisins are ground, mixed with 4 pounds of the whole canned raisins and added to 45 pounds of mix, an excellent raisin ice cream is obtained.

(c) Canning raisins for the ice cream trade: Numerous raisin preparations were canned and used experimentally in ice cream. The best method consisted in mixing equal quantities of ground and whole raisins prepared as described in $(a)$, heating to about $160^{\circ} \mathrm{F}$, canning and sealing hot, and then sterilizing in boiling water 45 minutes for small cans and 60 minutes for No. 10 cans. These raisins are ready to use, one No. 10 can being sufficient for 45 pounds of mix.

Dried Figs.-Dried figs are much less satisfactory than the fresh or the canned and are not recommended unless the former cannot be obtained. Black Mission, White Adriatic, Calimyrna, and Kadota dried figs were compared in respect to their suitability for use in ice cream. Of these, the Calimyrna proved best, with the Mission second. Neither of the other two varieties was entirely satisfactory. The addition of sugar in cooking was found desirable in order to prevent freezing of the fig meat to an icy texture in the ice cream.

Of the various methods of preparing the figs tested the following proved best: To 2 pounds of dried figs, add 3 quarts of water. Soak overnight. Add 11/2 pounds of sugar. Cook slowly until tenderabout 1 to $1 \frac{1}{2}$ hours. Weigh, and if the weight is less than 6 pounds, add water to make the weight. If it is more than 6 pounds, boil off excess water until a weight of about 6 pounds is attained. Cool and then grind. Add to 45 pounds of ice cream mix; the addition of a small amount of vanilla is usually desirable. Freeze to about 11 gallons.

The cooked whole figs and those cut in half, particularly Missions, are suitable for use in aufait.

Dried Apricots.-These are not nearly so satisfactory as the fresh or the canned. They may, however, be prepared and used as described for dried figs, except that $1 \frac{1}{2}$ pounds of fruit, 1 pound of sugar, and 3 quarts of water are used. Bring final cooked weight to 6 pounds.

Other Dried Fruits.-Dried pears, peaches, and apples are not recommended for use in ice cream. 


\section{INVESTIGATIONS ON THE USE OF FRESH FRUITS IN WATER ICES}

Water ices differ from sherbets in one respect: some ice cream mix or other form of milk solids is added to sherbets but none to water ices. Both consist essentially of fruit juice, sugar, water, and stabilizing colloid frozen to the consistency of ice cream. The water ices will be considered first as they are more important than the sherbets.

There is a large potential market for fruit ices, undeveloped principally because in the past fruit ices have been "poor keepers," often, if not usually, becoming rough in texture and "bleeding" before they have been dispensed. These defects are usually inherent in the basic water ice mixes used commercially.

Fruit ices are the ideal frozen dessert for summer months because they are acid in flavor and thus thirst quenching and refreshing. They deserve greater popularity than at present exists.

One very important cause for their relatively slight popularity is that mentioned in the introduction to this bulletin. In general, too small a proportion of fruit is used in so-called fruit ices, a fault which some ice cream manufacturer attempts to remedy by the addition of excessive amounts of color and flavor.

Comparison of Various Basic Water Ice Mixes.-In the earlier experiments, a basic mix containing gelatin as the colloid for stabilizing the ice was used. This mix consisted of:

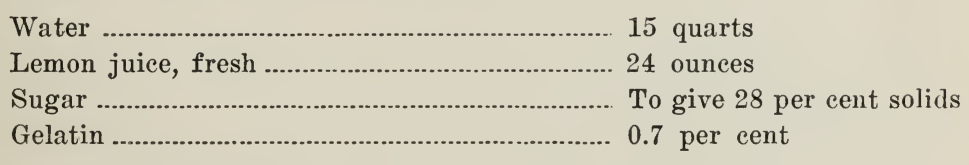

Except with orange and lemon juices, the gelatin reacted with the coloring matter and tannin of the fruit juice to give a grayish precipitate, which injured the appearance of the ice. All ices made with gelatin were short lived. They soon became rough in texture and bled; that is, the juice or syrup tended to separate from the ice crystals, giving a mass of ice in the top of the container and a syrup at the bottom.

Because the basic mix containing gelatin proved so unsatisfactory with fruit juices, various mixes developed in the investigation previously mentioned (see footnote, page 5) were tried, for the preparation of both small experimental and commercial lots of water ices. One new basic mix proved successful for use with juices. None of these colloids forms precipitates with constituents of the fruit juices. 
Furthermore, they give ices of remarkably long life, the ices having been kept in the hardening room for a month without appreciable "roughening" of the texture and "bleeding." Another very desirable characteristic is their freedom from disagreeable taste, if products of good quality are used. Many gelatins impart a disagreeable flavor to the ice or mask the fruit flavor.

It was found in other experiments that the acidity of the water ice greatly affected the texture and other qualities as well as the flavor, and that the best results were obtained with an acidity equivalent to 0.6 to 0.65 grams of acid (as citric) per $100 \mathrm{cc}$.

The investigations on the effect of composition of the basic mix on the quality of water ices were not an integral part of the investigations given in this bulletin. However, in applying the major results of the water ice investigations to actual practice, the following basic mix was found very satisfactory:

Cane sugar 21 pounds

Pure corn sugar crystals 7 pounds $^{9}$

Agar agar, highest grade powdered 0.15 pounds $\left(2 \frac{1}{2}\right.$ ounces $)$

Gum tragacanth, powdered 0.35 pounds $\left(5 \frac{1}{2}\right.$ ounces $)$

Make to 80 pounds with water, and add sufficient citric acid to give, when mixed with fruit or fruit juice, a final acidity of 0.6 per cent as citric. Ordinarily, this may be taken as about 6 to 8 ounces of citric acid to 100 pounds of mix after addition of fruit.

Proportion of Fruit.- In most cases 20 per cent by weight of fruit or fruit juice was used. Sometimes it may be necessary to use a greater proportion than this, where the flavor of the fruit is not very pronounced. If more than 20 per cent fruit is used, due allowance should be made in the basic mix by adding more colloids, i.e., agar agar and gum tragacanth, etc.

Fresh Apricot Ice.-As in ice cream, the cooked fresh apricots were found superior to the raw fruit for use in water ice. The following formula is based on this finding:

To 10 pounds of pitted, ground, thoroughly ripe apricots, add $21 / 2$ pounds of sugar. Boil three to five minutes and cool. Add 9 pounds to sufficient basic water ice mix to give 5 gallons. Freeze to not more than 35 per cent yield.

The basic mix in this case should be made with about 6 ounces of citric acid added to each 100 pounds of mix, or with lemon juice to give the desired acidity.

${ }^{9}$ Cerelose, pure commercial corn sugar, was used. 
Fresh Berry Ices.-Fresh berries are very satisfactory for use in water ices, strawberry ice being the most popular. Of the other common berries, loganberries and raspberries are probably best. Cranberry water ice is very popular during the holiday season.

Uncooked berries proved best for use in water ice. Cranberries were an exception, however, and were not at all satisfactory unless cooked before freezing.

Various proportions of berries and basic mix were tried with the conclusion that an addition of about 20 per cent of the prepared fruit to the basic mix gave the best results. More fruit than this made the ice too pulpy or jam-like; very much less made the flavor and color too dilute. The formulas given below are based on trials in the laboratory and on experience of the Dairy Industry Division in preparing water ices commercially.

(a) Blackberry, loganberry, raspberry, and strawberry ices: To 10 pounds of hulled, washed, crushed berries, add 3 pounds of cane sugar. Stir until dissolved. Add 9 pounds to basic water ice mix to give 5 gallons and citric acid to increase total acidity to 0.6 per cent; or, preferably, use a basic mix containing about 6 ounces of citric acid in 100 pounds of mix. Freeze to about 35 per cent yield.

See page 26 for formula for basic mix.

(b) Cranberry ice: Cranberries, it was found, give a rather bitter ice unless first blanched in boiling water. This is taken into account in the following formula:

To 9 pounds of cranberries, add 11/4 gallons of boiling water; allow to stand two minutes, then discard the water. Again add 1 gallon of water and $2 \frac{1}{2}$ pounds of sugar. Boil until the berries are soft. Rub through a colander or screen and add 9 pounds to basic water ice mix to give 5 gallons. Freeze to about 35 per cent yield.

Fresh Grape Ice.-In season, fresh grapes can be used to good advantage in water ice. Juice from thoroughly ripe Muscat grapes gave a very good water ice and a mixture of the Muscat and any red grape juice was also satisfactory. The eastern varieties such as Pierce Isabella and Concord were found superior to most California (Vinifera) varieties, for water ices.

To extract the juice from Muscat grapes, crush thoroughly and express the juice in a fruit juice press or by applying pressure to the crushed grapes in a sugar bag. The juice should be strained through cheesecloth or a sugar bag to remove coarse particles, but need not be perfectly clear. 
To extract the juice from red juice grapes, such as Pierce Isabella, Alicante Bouschet, and Zinfandel, crush thoroughly; heat to about $160^{\circ} \mathrm{F}$ and press or squeeze the juice through a bag.

Add no sugar. To $4 \frac{1}{2} 2$ to 5 quarts of the juice, add basic water ice mix to give 5 gallons. The basic mix should be prepared to contain about 6 ounces of citric acid per 100 pounds of mix. Freeze to not more than 35 per cent yield.

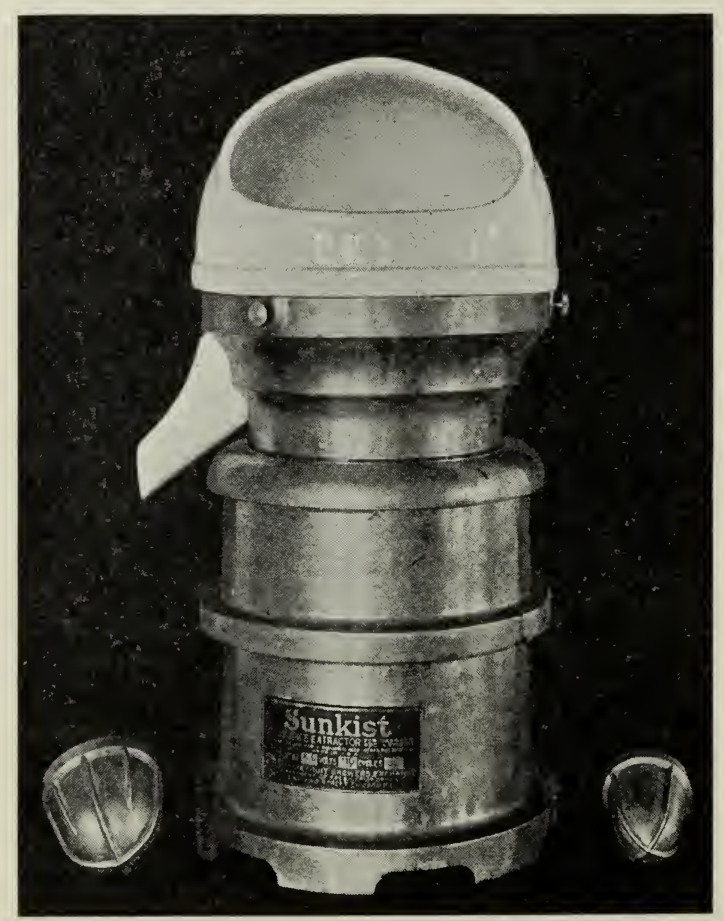

Fig. 4.-Revolving cone citrus juice extractor.

Fresh Lemon Ice.-Of the various proportions of lemon juice tested, about $71 / 2$ per cent gave the best results. The juice expressed on a revolving cone was found to be of better flavor for use in water ice than that expressed by pressing the whole fruit. The following formula has proved satisfactory.

Cut the lemons in half and express the juice. Strain out the seeds and coarse pieces of "rag." To 3 pints of the juice, add 3 pounds of sugar and 3 pints of water with basic mix to give 5 gallons. If the flavor is too faint, add a few drops of best quality lemon oil or extract. A small amount of lemon yellow color improves the appearance. The 
basic mix in this case should be made with about 4 ounces of citric acid in 100 pounds of mix. Lemon juice usually contains about 6 per cent citric acid. Freeze to not more than 35 per cent yield.

Fresh Orange Ice.-Orange ice made with the fresh juice is much superior in flavor to that made with syrups or concentrates. Most factories now use too little juice and altogether too much artificial color and flavor in their orange ice. About $4 \frac{1}{2} 2$ quarts of fresh juice with basic mix to give 5 gallons should be used. Where obtainable, cull oranges or "juice grade" oranges may be utilized. They are equally as good as the higher priced oranges for orange ice. The Valencia gave ices of slightly better flavor than the Navel, but the difference was slight. The basic mix should contain about 0.4 per cent acid before addition of the orange; that is, about 6 ounces of citric acid in 100 pounds of mix.

To prepare the ice: Extract the juice from the halved fruit on a revolving cone. Strain through a sieve or colander to eliminate seeds and very coarse pulp. To $4 \frac{1}{2}$ quarts of the juice, add basic mix to give 5 gallons. Add a small amount, not too much, orange color if needed, and a very small amount of orange oil. Freeze to about 35 per cent yield.

Fresh Peach Ice.-The common canning and drying varieties of peaches did not prove satisfactory in ice. .If highly flavored, juicy table peaches are obtainable, peel and proceed as directed for apricot ice.

Fresh Plum Ice.-In experiments made at the Lincoln Cannery by one of the authors ${ }^{10}$ in 1922 , it was found that highly colored varieties of plums such as the Damson, Blue Diamond, Satsuma, and Grand Duke were satisfactory for use in water ices. As a result of these experiments, the following procedure is recommended:

Use thoroughly ripe-plums. Crush. To 10 pounds of plums, add 1 gallon of water. Boil four to five minutes. Strain through a sugar bag. To each gallon of juice, add 3 pounds of sugar. To $4 \frac{1}{2}$ quarts of the sweetened juice add basic water ice mix to give 5 gallons. Freeze to about 35 per cent yield. The basic mix used should contain about 5 ounces of citric acid in 100 pounds.

Fresh Pomegranate Ice.-Because of the great difficulty in expressing the juice in the average ice cream plant, it is recommended that only the bottled juice be used. See page 30 .

ro See Cruess, W. V. Utilization of surplus plums. California Agr. Exp. Sta. Bul. $400: 1-21.1926$. 


\section{INVESTIGATIONS ON THE USE OF BOTTLED FRUIT JUICES IN WATER ICES}

Fresh fruit juices are naturally better than the juice preserved by heat or other means, but unfortunately the season for most fresh fruits is short and for many fruits does not correspond with the period of greatest demand for fruit ices. Consequently, it becomes necessary to use the preserved juices to some extent.

Bottled grape juice, loganberry, and pomegranate juices preserved by pasteurization are obtainable. It is most economical to buy the juices by the case in gallon bottles.

Bottled loganberry, grape, pomegranate, lemon, orange, blackberry, strawberry, and apple juices were tried. The citrus juices were very unsatisfactory because of their pronounced cooked flavor; and in some cases, especially in samples more than six months old, there was a very disagreeable "stale" or "turpentiney" flavor. Other investigations have proved that there is at present no practicable method of preserving fresh citrus juices except by freezing in storage or by conversion into syrups or concentrates.

Pomegranate, grape, loganberry, and blackberry juices were satisfactory. The pomegranate and berry juices were slightly sweetened with sugar before bottling; the grape was not sweetened. These juices gave good results when used in the same manner as the fresh; that is, $4 \frac{1}{2}$ quarts of juice were added to sufficient basic water ice mix to give 5 gallons. Pomegranate is the least desirable because of its rather mild flavor.

Strawberry juice a few weeks after bottling was of very poor color and much inferior to the fresh berries in flavor. The cold-pack strawberries are the only satisfactory substitute for the fresh, all things considered.

A satisfactory ice was made with apple juice, but compared with fresh strawberry, grape, and orange ices it was rather insipid. It seems to have no very great commercial possibilities in this state; consumers prefer to use unfermented cider as a beverage.

\section{INVESTIGATIONS ON THE USE OF FRUIT CONCENTRATES IN WATER ICES}

Fruit concentrates are the natural fruit juices concentrated to the consistency of syrups. Usually very little or no sugar is added. Facilities exist in several fruit products factories in this state for the concentration of fruit juices in vacuo in glass-lined vacuum pans, and 
in other factories by the freezing process. A number of different commercially and experimentally prepared concentrates were tried. Of these, orange and grape concentrates were the most satisfactory. Concentrates made from various berries and pomegranates by vacuum concentration were very unsatisfactory because they lacked flavor and had poor color. In some cases, the concentration had caused the products to take on a very disagreeable, astringent taste. Most of those concentrated in metal vacuum pans possessed a metallic taste. A sweetened pineapple concentrate gave fair results.

Juices concentrated by freezing possessed much more of the fresh flavor of the fruit than did those made by vacuum concentration. Lemon concentrate was dark brown in color and of stale lemon flavor, and was wholly unsuited to use in water ice.

If the technique ${ }^{11}$ of preparing fruit concentrates is improved so that the fresh fruit flavor and color are well retained, there should be a considerable market for such products in the ice cream industry.

Only the orange and grape concentrates will be discussed further, owing to the fact that the other concentrates were either entirely unsatisfactory or require great improvement in the present method of manufacture in order to render them very satisfactory for use in water ices. ${ }^{12}$

Orange Concentrate.-T'wo commercially prepared bottled orange concentrates were tried. Some of each was used when first received, and portions of each were stored at room temperature and at the temperature of the ordinary ice cream hardening room, zero to $5^{\circ} \mathrm{F}$. The freshly prepared concentrates and those held at zero to $5^{\circ} \mathrm{F}$ even for three years were fairly satisfactory for use in water ice, provided a small amount of fresh juice was also used to mask the cooked taste of the concentrate. The concentrates stored at room temperature soon darkened in color, finally becoming almost black, and also acquired a strong medicinal or "stale" orange flavor. It is, therefore, recommended that, when orange concentrate is used, it be purchased within a few days after manufacture, and that the concentrates be stored in the hardening room or used very soon after purchase.

Numerous experimental lots of orange ice were prepared with the concentrate, different proportions of concentrate being used with and without the addition of fresh juice.

11 For details of various processes of concentrating fruit juices see: Irish, J. H. Fruit juice concentrates. California Agr. Exp. Sta. Bul. 392:1-20. 1925.

12 The names of manufacturers of fruit concentrates and fruit juices will be sent upon request, to: Division of Viticulture and Fruit Products, University of California, Berkeley. 
The following formula gave the best results :

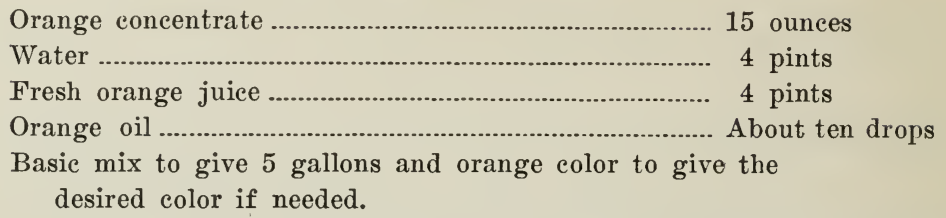

The basic mix should be prepared with about 6 ounces of citric acid in 100 pounds of mix.

Grape Concentrate.--Only grape concentrate of red color was found satisfactory. The color must be a deep purplish red, not a reddish brown. The addition of some fresh or bottled grape juice is desirable in order to furnish flavor. The following formula can be recommended :

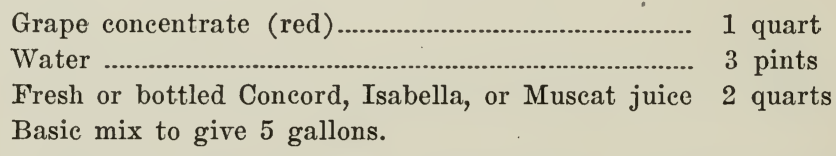

The basic mix should be made with about 6 ounces of citric acid in 100 pounds of mix.

\section{INVESTIGATIONS ON THE USE OF FRUIT SYRUPS IN WATER ICES}

Fruit syrups differ from fruit concentrates in that they are prepared by the addition of sufficient cane or beet sugar to give a syrupy consistency. They may be preserved by heat, cold storage, or sodium benzoate, or by very high sugar content (above 70 per cent).

A number of these were used in the preparation of water ices. While they were fairly satisfactory in most eases, their high sugar content made considerable dilution with water necessary in order not to depress the freezing point of the water ice too greatly and at the same time maintain the proper balance between the sugars.

Blackberry and loganberry syrups were found particularly good in flavor and color; strawberry syrup possessed a pronounced fresh berry flavor but lacked color. Orange syrup was quite satisfactory if not subjected to prolonged storage (three months or longer) before use, or if stored at $32^{\circ} \mathrm{F}$ or a lower temperature. In freezing storage (zero to $10^{\circ} \mathrm{F}$ ), orange syrup retained its flavor for more than three and a half years.

In general, it was found that the fruit syrups diluted with three volumes of water to one volume of syrup could be used to replace the fresh juices in the formulas previously given. See pages 27-30. However, not less than 6 quarts of the diluted syrups should be used with basic mix to give 5 gallons. 


\section{THE USE OF FRUITS IN OTHER FROZEN DESSERTS AND SPECIALTIES}

There are several other frozen desserts in which fruits are customarily used, or to which fruits may be added to good advantage. One of these, frozen plum pudding, is very popular during the holiday season. Several others described below are worthy of consideration and deserve greater popularity.

Frozen Plum Pudding.-This product is made with cream, to which are added various dried and candied fruits, nuts, and usually eggs. It is a very rich dessert, but is in demand for the Thanksgiving and Christmas holiday dinners. There are a number of formulas, of which. the following is typical $:^{13}$

5 to 10 dozen egg yolks

1 pound cocoa

4 pounds cherries and assorted fruits

1 to 2 pounds raisins

2 pounds figs (dry)

1 pound walnut meats

3 tablespoonfuls ground cinnamon

$1 / 2$ teaspoonful ground cloves.

45 pounds of standard or high fat mix.

(Spices should be stirred into the fruits before adding to the cream.)

Beat the egg yolks with the mix (1 dozen egg yolks to 1 quart of mix), heat slowly to $145^{\circ} \mathrm{F}$, and add to the remainder of the mix. Add the mixture of fruits, nuts, chocolate, and spices during freezing.

Nesselrode Pudding.-A satisfactory formula in commercial use is as follows:

1 pound assorted fruit

6 pounds maraschino cherries

2 pounds pineapple

6 pounds candied cherries

4 pounds raisins

4 pounds macaroons

4 pounds almonds

Ground together

5 to 10 dozen egg yolks (preparation same as for plum pudding)

Full portion vanilla

Color, gold

45 pounds standard or high fat mix.

Tutti Frutti Ice Cream (Parfait).- There are many formulas in commercial use for this ice cream, candied and sweetened crushed fruits generally being used instead of the fresh or cold-pack fruits.

13 This formula and the one for Nesselrode pudding, from: Turnbow, G. D. and L. A. Raffetto. Ice cream. John Wiley \& Sons. (In press.) 
The following formula has been found satisfactory:

5 to 10 dozen egg yolks

3 pounds candied cherries or maraschino cherries

2 to 3 pounds of candied assorted fruits

3 pounds pineapple

Full portion of vanilla

45 pounds of standard or high fat mix.

The pits should be removed from the assorted fruits, which should all be ground before being added to the ice cream. It is desirable to soak the cherries and other fruits in the juice of the pineapple overnight. This cream is popular in bricks and in combination with other creams.

Crushed fruit mixtures prepared especially for use in tutti frutti are obtainable and satisfactory.

Aufait.-Aufait is a brick ice cream consisting of layers of one or more kinds of cream with layers of fruit, whole or in large pieces, between them. Halved candied figs, whole candied cherries, pieces of other candied fruits, various well drained fruit preserves, and well cooked dried figs cut in half, can be used in aufait. The aufait is especially good if one or more layers of the brick consist of fruit ice creams such as orange, strawberry, or pineapple.

Lacto.-Lacto is made with skim or whole milk, soured with lactic acid culture, and mixed with sugar and eggs. Fruit juices may be added. The following formula is typical:

Lacto milk (starter, slightly sour skim or whole milk)

6 gallons

Sugar

18 pounds

Eggs

2 dozen

Lemon juice

3 pints

Use a small amount of stabilizer.

Fruit juice or crushed fruit (with sugar added if necessary) 2 quarts

Dissolve the sugar in the "lacto milk." Beat the egg whites and yolks separately. Add to the milk and strain through a fine screen or gauze. Add the fruit juices and freeze. Draw 20 per cent less yield than for ice cream.

Fruit Mousse.-Crushed fruits and fruit juices are ideally suited to use in this class of frozen desserts. The following formula is typical. It may be varied to suit the nature of the fruit and other conditions. Whip 2 gallons of 35 per cent cream and 4 pounds of sugar in the freezer. Slowly add $21 / 2$ gallons of soft ice cream as drawn from the freezer. The mixture should be whipped just enough to mix thor- 
oughly. Flavor with 1 gallon of fruit pulp or fruit juice and color as desired. This formula adds more solids to the cream and does not have the tendency to stratify or become grainy, as is the case when only cream is whipped.

Frozen Fruit Punch.-Before the advent of national prohibition, frozen fruit punches were usually prepared with fermented fruit juices, or other alcoholic beverages were added. Experiments, however, have demonstrated that excellent fruit punches can be made with the unfermented juices.

In the Fruit Products Laboratory, the following formula, among others, has proved satisfactory:

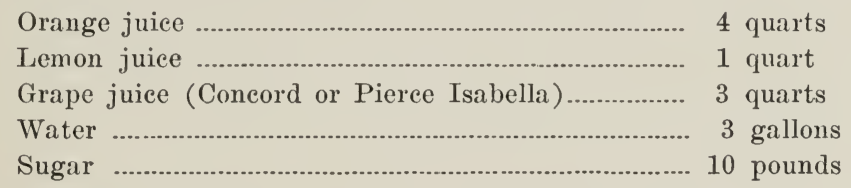

The addition of approximately 2 per cent, that is, $3 \frac{1}{4}$ ounces of gum tragacanth, will cause the texture to be smoother and the keeping quality better after freezing.

Other fruit juices may be substituted for the grape juice. If these are very sour juices such as loganberry, use less lemon juice.

The combinations of juices that may be used in punch are numerous. Pineapple, loganberry, strawberry, blackberry, raspberry, and pomegranate juices are particularly desirable additions. The syrup from cold-pack berries and from maraschino cherries possesses great flavoring power in fruit punches.

Fruit Frappés.-A frappé is an ice consisting of water, sugar, and natural flavoring, and chilled to a soft, semi-frozen consistency. It is similar in compositoin to sherbets and water ices. Fruit juices may be used to excellent advantage in this product.

Frozen "Suckers." - Recently a specialty known by the trade as "frozen suckers" has appeared on the market, and in some localities has proved fairly popular. The product is prepared by placing ordinary soda water, not carbonated, in glass tubes and freezing solid. Before freezing a wooden skewer is inserted in the liquid to furnish a handle for holding the frozen sucker as it is consumed. The tubes are immersed in warm water for a moment to melt the ice so that the frozen suckers may be removed. The suckers are wrapped in paper and packed in ice cream cans surrounded by salt and ice.

Until the present, they have been made by diluting with water such standard soda water syrups as ginger ale and the various imitation fruit syrups, such as orange, lemon, grape, strawberry, etc. 
Experiments by J. H. Irish of the Fruit Products Laboratory with fruit juices and fruit syrups diluted with water evidenced their superiority in flavor to the imitation fruit products for the preparation of pure fruit frozen suckers.

The sugar content of the juices or syrup must not be greater than about 15 per cent-liquids testing about $12^{\circ}$ Balling gave the best results. If too high in solids, that is, "too sweet," the product either will not solidify or will be soft. If too dilute, it will be too hard when frozen and will lack flavor.

That the frozen suckers made from artificially flavored and colored imitation fruit have not proved very popular is due, no doubt, to the fact that they are imitation rather than real fruit juices. Frozen fruit juices of good quality should prove popular, particularly among school children. An orange product of this sort could probably be introduced in the schools with very little difficulty.

\section{SUMMARY}

Investigations have been conducted cooperatively during the past three years by the Dairy Industry Division and the Fruit Products Laboratory of the University of California on the use of fresh fruits and various fruit products in ice cream, water ices, and frozen specialties. The following are the more important results.

1. Most commercial manufacturers use too small a proportion of fruit in fruit ice cream and ices. Furthermore, the state legal minimum of 3 per cent fruit in fruit ice creams is altogether too low, except for fruit products that contain a large amount of added artificial flavor.

2. A basic ice cream mix containing about 40-41 per cent solids gave better results with fruits than did a mix of about 35 per cent solids; the texture was smoother and the flavor richer.

3. Satisfactory formulas were developed for the preparation of fresh apricot, avocado, banana, fig, peach, pear, and berry ice creams, the principal improvement over previously existing formulas being the use of a larger proportion of fruit. Avocados, Calimyrna figs, and persimmons gave exceptionally good ice creams and indications of unusual commercial promise. Most of the canning and drying varieties of peaches lacked flavor and were not nearly so satisfactory as some of the more highly flavored, soft, table varieties.

Not less than four pounds of fresh strawberries to 45 pounds of basic mix was necessary for a good strawberry ice cream. 
4. Properly prepared and stored cold-pack fruits were found to be approximately equal to the fresh for use in ice cream and water ices. Sealed were much better than open containers for the storage of coldpack fruits. Economical and satisfactory methods of cold packing and storing fresh fruits were developed.

5. Unexpectedly, it was found that the lowest and least costly grade of commercially canned fruits, namely Solid Pack Pie Grade, is the most satisfactory grade for use in ice creams or ices. Canned figs, in particular, gave an excellent ice cream which has proved popular when placed on the market. Apricots were also very satisfactory. Canned peaches lacked flavor. Bartlett pears gave a fairly satisfactory ice cream of mild flavor.

6. Preserves and jams were not very satisfactory because they were too sweet and too costly. Their high sugar content reduced the freezing point and caused the ice cream to be soft.

7. Methods of preparing and preserving as well as using maraschino cherries were studied.

8. Bottled fruit juices, concentrates, and syrups were used experimentally in ice cream and ices and satisfactory formulas developed for these products made from suitable fruits. Concentrates are convenient to store and use, but unfortunately most of those that have thus far been produced commercially are lacking in flavor, or deteriorate very rapidly during storage at room temperature.

9. Broken pieces and ground or chopped candied fruits, by. products of candied fruit factories, were found very satisfactory for use in specialties such as tutti frutti ice cream.

10. Prunes gave the best results of all dried fruit studied, and because of their health value, ice cream made with prunes should have great commercial possibilities. Raisin ice cream made with Muscat raisins was excellent; that made with Thompson seedless was decidedly lacking in flavor. Other dried fruits are so much inferior to the canned fruits that their use is not recommended unless the canned is unobtainable.

11. Puddings, tutti frutti, aufait, lacto, mousses, punch, and frappés, all contain fruit or are improved by its addition. Frozen "suckers" made with fruit juices were very much superior to those made with the imitation fruit or artificially colored and flavored liquids heretofore used commercially. 


\section{ACKNOWLEDGMENTS}

The authors desire to express their appreciation to J. H. Irish, Assistant Chemist in the Fruit Products Laboratory; to H. A. Spilman of the Dairy Industry Division; and to E. E. Brown, Student Assistant, for valuable assistance in these investigations. We also desire to thank Wilbur Thomas and Albert Ernst of Hage's Ice Cream Co., San Diego, for cooperation in commercial scale experiments and for suggestions and corrections offered during preparation of the manuscript. 
No.

275. The Cultivation of Belladonna in California.

276. The Pomegranate.

277. Sudan Grass.

278. Grain Sorghums.

279. Irrigation of Rice in California.

283. The Olive Insects of California.

294. Bean Culture in California.

304. A Study of the Effects of Freezes on Citrus in California.

310. Plum Pollination.

312. Mariout Barley.

313. Pruning Young Deciduous Fruit Trees.

319. Caprifigs and Caprification.

324. Storage of Perishable Fruit at Freez ing Temperatures.

325. Rice Irrigation Measurements and Experiments in Sacramento Valley, 1914-1919.

328. Prune Growing in California.

331. Phylloxera-Resistant Stocks.

835. Cocoanut Meal as a Feed for Dairy Cows and Other Livestock.

339. The Relative Cost of Making Logs from Small and Large Timber.

340. Control of the Pocket Gopher in California.

343. Cheese Pests and Their Control.

344. Cold Storage as an Aid to the Marketing of Plums.

346. Almond Pollination.

347. The Control of Red Spiders in Deciduous Orchards.

348. Pruning Young Olive Trees.

349. A Study of Sidedraft and Tractor Hitches.

350. Agriculture in Cut-over Redwood Lands.

352. Further Experiments in Plum Pollination.

353. Bovine Infectious Abortion.

354. Results of Rice Experiments in 1922.

357. A Self-mixing Dusting Machine for Applying Dry Insecticides and Fungicides.

358. Black Measles, Water Berries, and Related Vine Troubles.

361. Preliminary Yield Tables for Second Growth Redwood.

362. Dust and the Tractor Engine.

363. The Pruning of Citrus Trees in California.

364. Fungicidal Dusts for the Control of Bunt.

365. Avocado Culture in California.

366. Turkish Tobacco Culture, Curing and Marketing.

367. Methods of Harvesting and Irrigation in Relation of Mouldy Walnuts.

368. Bacterial Decomposition of Olives during Pickling.

369. Comparison of Woods for Butter Boxes.

370. Browning of Yellow Newtown Apples.

371. The Relative Cost of Yarding Small and Large Timber.

372. The Cost of Producing Market Milk and Butterfat on 246 California Dairies.

373. Pear Pollination.

374. A Survey of Orchard Practices in the Citrus Industry of Southern California.

375. Results of Rice Experiments at Cortena, 1923.

376. Sun-Drying and Dehydration of Walnuts.

377. The Cold Storage of Pears.

379. Walnut Culture in California.

380. Growth of Eucalyptus in California Plantations.

381. Growing and Handling Asparagus Crowns.
No.

382. Pumping for Drainage in the San Joaquin Valley, California.

383. Monilia Blossom Blight (Brown Rot) of Apricot.

385. Pollination of the Sweet Cherry.

386. Pruning Bearing Deciduous Fruit Trees.

387. Fig Sraut.

388. The Principles and Practice of Sundrying Fruit.

389. Berseem or Egyptian Clover.

390. Harvesting and Packing Grapes in California.

391. Machines for Coating Seed Wheat with Copper Carbonate Dust.

392. Fruit Juice Concentrates.

393. Crop Sequences at Davis.

394. Cereal Hay Production in California. Feeding Trials with Cereal Hay.

395. Bark Diseases of Citrus Trees.

396. The Mat Bean (Phaseolus aconitifolius).

397. Manufacture of Roquefort Type Cheese from Goat's Milk.

398. Orchard Heating in California.

399. The Blackberry Mite, the Cause of Redberry Disease of the Himalaya Blackberry, and its Control.

400. The Utilization of Surplus Plums.

401. Cost of Work Horses on California Farms.

402. The Codling Moth in Walnuts.

403. Farm-Accounting Associations.

404. The Dehydration of Prunes.

405. Citrus Culture in Central California.

406. Stationary Spray Plants in California.

407. Yield, Stand and Volume Tables for White Fir in the California Pine Region.

408. Alternaria Rot of Lemons.

409. The Digestibility of Certain Fruit By. products as Determined for Ruminants.

410. Factors Affecting the Quality of Fresh Asparagus after it is Harvested.

411. Paradichlorobenzene as a Soil Fumigant.

412. A Study of the Relative Values of Certain Root Crops and Salmon Oil as Sources of Vitamin A for Poultry.

413. The California Poultry Industry; a Statistical Study.

414. Planting and Thinning Distances for Deciduous Fruit Trees.

415. The Tractor on California Farms.

416. Culture of the Oriental Persimmon in California.

417. Poultry Feeding: Principles and Practice.

418. A Study of Various Rations for Finishing Range Calves as Baby Beeves.

419. Economic Aspects of the Cantaloupe Industry.

420. Rice and Rice By-products as Feeds for Fattening Swine.

421. Beef Cattle Feeding Trials, 1921-24.

422. Cost of Producing Almonds in California; a Progress Report.

423. Apricots (Series on California Crops and Prices)

424. The Relation of Rate of Maturity to Egg Production.

425. Apple Growing in California.

426. Apple Pollination Studies in California.

427. The Value of Orange Pulp for Milk Production.

428. The Relation of Maturity of California Plums to Shipping and Dessert Quality. 
No.

87. Alfalfa.

117. The Selection and Cost of a Small Pumping Plant.

127. House Fumigation.

129. The Control of Citrus Insects.

136. Melilotus indica as a Green-Manure Crop for California.

144. Oidium or Powdery Mildew of the Vine.

157. Control of the Pear Scab.

160. Lettuce Growing in California.

164. Small Fruit Culture in California.

166. The County Farm Bureau.

170. Fertilizing California Soils for the 1918 Crop.

173. The Construction of the Wood-Hoop Silo.

178. The Packing of Apples in California.

179. Factors of Importance in Producing Milk of Low Bacterial Count.

190. Agriculture Clubs in California.

199. Onion Growing in California.

202. County Organizations for Rural Fire Control.

203. Peat as a Manure Substitute.

209. The Function of the Farm Burean.

210. Suggestions to the Settler in California.

212. Salvaging Rain-Damaged Prunes.

215. Feeding Dairy Cows in California.

217. Methods for Marketing Vegetables in California.

220. Unfermented Fruit Juices.

228. Vineyard Irrigation in Arid Climates.

230. Testing Milk, Cream, and Skim Milk for Butterfat.

231. The Home Vineyard.

232. Harvesting and Handling California Cherries for Eastern Shipment.

234. Winter Injury to Young Walnut Trees during 1921-22.

235. Soil Analysis and Soil and Plant Inter-relations.

236. The Common Hawks and Owls of California from the Standpoint of the Rancher.

237. Directions for the Tanning and Dressing of Furs.

238. The Apricot in California.

239. Iarvesting and Handling Apricots and Plums for Eastern Shipment.

240. Harvesting and Handling Pears for Eastern Shipment.

241. Harvesting and Handling Peaches for Eastern Shipment.

243. Marmalade Juice and Jelly Juice from Citrus Fruits.

244. Central Wire Bracing for Fruit Trees.

245. Vine Pruning Systems.

247. Colonization and Rural Development.

248. Some Common Errors in Vine Pruning and Their Remedies.

249. Replacing Missing Vines.

250. Measurement of Irrigation Water on the Farm.

252. Supports for Vines.

253. Vineyard Plans.

254. The Use of Artificial Light to Increase Winter Egg Production.
No.

255. Leguminous Plants as Organic Fertilizer in California Agriculture.

256. The Control of Wild Morning Glory.

257. The Small-Seeded Horse Bean.

258. Thinning Deciduous Fruits.

259. Pear By-products.

261. Sewing Grain Sacks.

262. Cabbage Growing in California.

263. Tomato Production in California.

264. Preliminary Essentials to Bovine Tuberculosis Control.

265. Plant Disease and Pest Control

266. Analyzing the Citrus Orchard by Means of Simple Tree Records.

267. The Tendency of Tractors to Rise in Front; Causes and Remedies.

269. An Orchard Brush Burner.

270. A Farm Septic Tank.

272. California Farm Tenancy and Methods of Leasing.

273. Saving the Gophered Citrus Tree.

274. Fusarium Wilt of Tomato and its Con trol by Means of Resistant Varieties.

276. Home Canning.

277. Head, Cane, and Cordon Pruning of Vines.

278. Olive Pickling in Mediterranean Countries.

279. The Preparation and Refining of Olive Oil in Southern Europe.

281. The Results of a Survey to Determine the Cost of Producing Beef in California.

282. Prevention of Insect Attack on Stored Grain.

283. Fertilizing Citrus Trees in California.

284. The Almond in California.

285. Sweet Potato Production in California.

286. Milk Houses for California Dairies.

287. Potato Production in California.

288. Phylloxera Resistant Vineyards.

289. Oak Fungus in Orchard Trees.

290. The Tangier Pea.

291. Blackhead and Other Causes of Loss of Turkeys in California.

292. Alkali Soils.

293. The Basis of Grape Standardization.

294. Propagation of Deciduous Fruits.

295. The Growing and Handling of Head Lettuce in California.

296. Control of the California Ground Squirrel.

298. The Possibilities and Limitations of Coöperative Marketing.

299. Poultry Breeding Records.

300. Coccidiosis of Chickens.

301. Buckeye Poisoning of the Honey Bee.

302. The Sugar Beet in California.

303. A Promising Remedy for Black Measles of the Vine.

304. Drainage on the Farm.

305. Liming the Soil.

306. A General Purpose Soil Auger and its Use on the Farm.

307. American Foulbrood and its Control. 308. Cantaloupe Production in California.

309. Fruit Tree and Orchard Judging.

The publications listed above may be had by addressing

College of Agriculture,

University of California,

Berkeley, California. 